Check for updates

Cite this: Chem. Commun., 2021, 57,919

Received 20th November 2020

Accepted 18th December 2020

DOI: $10.1039 / d 0 c c 07625 b$

rsc.li/chemcomm

\section{Regioselective side-chain amination of 2-alkyl azacycles by radical translocation: total synthesis of tetraponerine $\mathrm{T} 8 \dagger$}

\author{
Samuel D. Griggs, (D) Alejandro Martin-Roncero, (D) Adam Nelson (D)* and \\ Stephen P. Marsden (D)*
}

The regioselective $\gamma-\mathrm{C}-\mathrm{H}$ amination of the side-chain of saturated 2-alkyl nitrogen heterocycles is reported, proceeding through a sulfamide-directed 1,6-radical translocation. The practicality of this rapid access to 1,3-diamines is highlighted in a short synthesis of the alkaloid tetraponerine T8 and non-natural analogues.

The prevalence of nitrogen-containing molecules in nature and pharmaceuticals has inspired the development of general methods for $\mathrm{C}-\mathrm{N}$ bond synthesis. A common and important structural unit found in natural products and pharmaceuticals is the 1,3 -diamine motif, ${ }^{1}$ a valuable but synthetically challenging sub-class of which involves saturated nitrogen heterocycles bearing a 2-(aminoethyl) side-chain. This motif is exemplified by natural products such as cermizine $\mathrm{D}^{2}$ and the AMPA receptor antagonist kaitocephalin, ${ }^{3}$ as well as synthetic pharmaceuticals such as the antipsychotic thioridazine and the selective 5-HT7receptor antagonist SB-269970 (Fig. 1, panel A). Simpler 2-alkylsubstituted nitrogen heterocycles are more readily synthetically accessible and occur, for example, in biologically active natural products such as coniine and solenopsin (Fig. 1, panel B). Inspired by recent advances in direct $\mathrm{C}\left(\mathrm{sp}^{3}\right)-\mathrm{H}$ amination, ${ }^{4,5}$ we considered that the development of a method for the direct $\gamma$-amination of 2-alkyl nitrogen heterocycles would be an attractive approach to biologically-relevant 1,3-diamines (Fig. 1, panel C).

The approach we chose to take is based upon radical translocation chemistry. The use of nitrogen-centred radicals to perform regioselective hydride abstraction is well documented: the long-established Hofmann-Löffler-Freytag reaction uses aminium radicals (photochemically-generated from $N$-chloroamines) to perform intramolecular 1,5-hydrogen atom transfer (HAT); ${ }^{6}$ subsequent halogen abstraction by the resulting carbon-centred

Department of Chemistry, University of Leeds, Leeds, LS2 9JT, UK.

E-mail: s.p.marsden@leeds.ac.uk

$\dagger$ Electronic supplementary information (ESI) available. CCDC 2045420-2045422. For ESI and crystallographic data in CIF or other electronic format see DOI: 10.1039/d0cc07625b radical and intramolecular substitution with the amine forms pyrrolidines. Nitrogen-centred radicals substituted with electronwithdrawing sulfonyl or carbonyl groups have subsequently been harnessed to perform a variety of synthetically useful processes initiated by 1,5 -HAT through a kinetically favoured 6-membered transition state. ${ }^{7-13}$ Recently, intriguing regiocomplementary reactions have been reported, wherein $N$-centred radicals derived from sulfamate esters, ${ }^{14-22}$ and sulfamides ${ }^{22-26}$ have been reported instead to undergo 1,6-HAT reactions, with the change in selectivity being attributed to the long bonds and narrow bond angles in the sulfamate/sulfamide. ${ }^{16}$ The resulting radicals are frequently trapped by halogenation, with subsequent inter- ${ }^{24}$ or intramolecular ${ }^{14,22} \mathrm{C}-\mathrm{N}$ bond formation being observed in some cases with activated (benzylic or tertiary alkyl) substrates. While all the examples to date have utilised linear substrates, we recognised
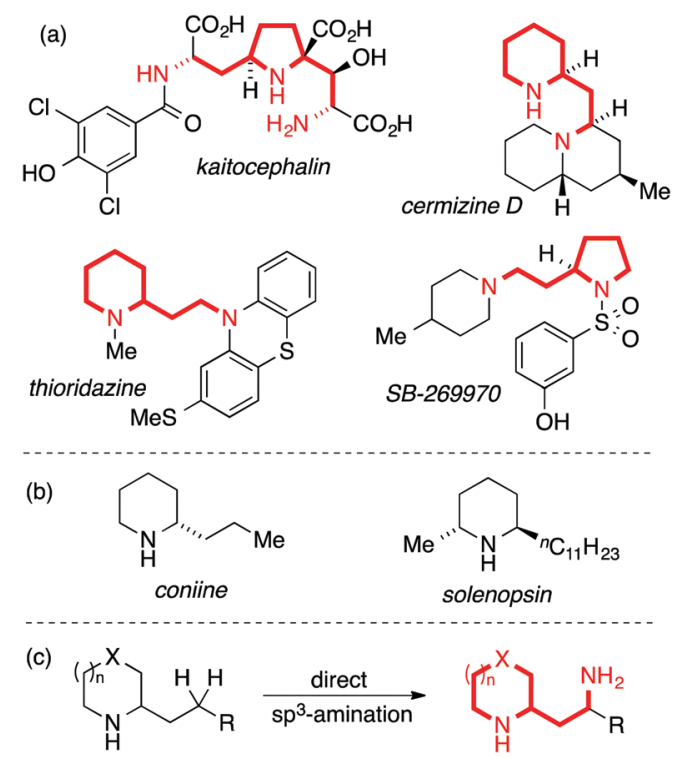

Fig. 1 Natural products and pharmaceuticals bearing the 1,3-diamine moiety. 

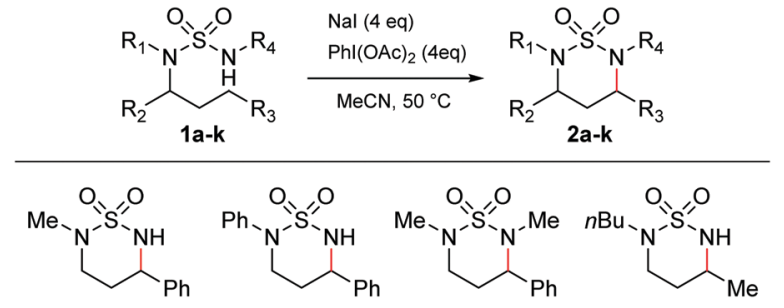

$$
\text { 2a, } 83 \% \quad \text { 2b, } 46 \% \quad \text { 2c, } 25 \% \quad \text { 2d, } 78 \%
$$

$39 \%^{a}$

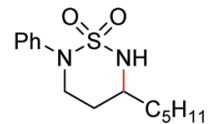

2e, $20 \%$

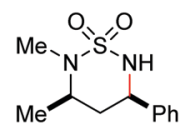

2f, $68 \%$

$67: 33 \mathrm{dr}$

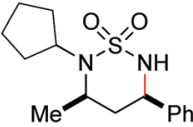

2g, $63 \%$

$63: 37 \mathrm{dr}$

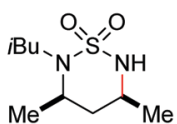

2h, $52 \%$

56:44 dr

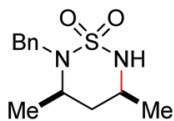

2i, $75 \%$

58:42 dr

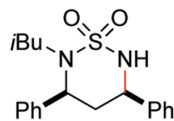

2j, $75 \%$

70:30 dr

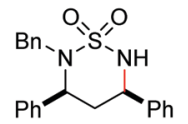

2k, $69 \%$

$71: 29 d r$
Scheme 1 Substrate scope of acyclic sulfamides. ${ }^{\text {a }}$ Reaction carried out with fluorescent light instead of heating.

that sulfamide derivatives of cyclic amines might initiate a 1,6-HAT to alkyl substituents at the 2-position, leading potentially to sidechain functionalisation. We report herein the successful demonstration of this radical translocation method for 1,3-diamine synthesis and application in the synthesis of a member of the tetraponerine alkaloids and analogues.

At the outset, we aimed to find conditions which would lead directly to the formation of cyclic sulfamides from the parent sulfamide without isolation of $N$-halogenated derivatives. ${ }^{14,22}$ We therefore conducted reaction scoping on simple acyclic sulfamide derivatives. Attempts to initiate $\mathrm{C}-\mathrm{H}$ amination of the phenylpropyl sulfamide 1a employing $\mathrm{I}_{2}$ and $\mathrm{PhI}(\mathrm{OAc})_{2}$ with heat at $50{ }^{\circ} \mathrm{C}$ resulted in a complex mixture of products. We consequently tried $\mathrm{NaI}$ and $\mathrm{PhI}(\mathrm{OAc})_{2}$, which would allow the in situ formation of $\mathrm{I}_{2} \cdot{ }^{12}$ Irradiating sulfamide $1 \mathrm{a}$ with visible light with $\mathrm{NaI}$ and $\mathrm{PhI}(\mathrm{OAc})_{2}$ gave the $\mathrm{C}-\mathrm{H}$ aminated product 2a in a $39 \%$ yield (Scheme 1). Carrying out the reaction under thermal conditions, however, gave rise to $2 \mathrm{a}$ in a superior $83 \%$ yield. In both cases, a single regioisomer was formed, being the expected product of 1,6-hydride abstraction.

A series of acyclic sulfamides $\mathbf{1 b}-\mathbf{k}$ was then synthesised from the linear alkyl amine ${ }^{27,28}$ which varied both the non-reacting $\mathrm{N}$-substituents and $\mathrm{N}$-alkyl chain undergoing amination, in order to probe the substrate tolerance of the reaction. Keeping the phenylpropyl side-chain as the reactive substituent, the $N$-phenyl and the $N, N^{\prime}$-dimethyl sulfamides both underwent reaction to give cyclic sulfamides $\mathbf{2 b}$ and $\mathbf{2 c}$, albeit in lower yields than for 1a. Importantly, reaction of the $N, N$-dibutylsulfamide $1 \mathbf{d}$ gave the cyclised product $\mathbf{2 d}$ in a pleasing $78 \%$ yield, demonstrating that, complementary to the prior literature reports, ${ }^{22}$ cyclisation under our conditions was not limited to activated benzylic positions. A related $N$-phenyl sulfamide could also be cyclised (2e), but again in lower yield than for the $N$-alkyl derivatives.
Finally, we probed the issue of stereochemistry in the cyclisations by examining insertion to chiral variants. Cyclisation of various $N, N$-dialkylsulfamides bearing $\alpha$-chiral substituents (2f-2k) was effected with no detriment to the reaction yields, giving rise to mixtures of diastereomeric products with moderate diastereoselectivity (up to $c a .70: 30$ ). The major diastereomer was identified as the cis isomer in all cases by NMR spectroscopy (ESI $†$ ). The origins of the diastereoselectivity are uncertain. The reaction likely proceeds by initial iodination of the prochiral carbon-centred radical generated by 1,6-HAT. This process is unlikely to be stereoselective, but in the presence of excess iodide the two diastereomeric iodides may potentially be interconverted by Finkelstein substitution, with subsequent cyclisation to the diequatorial cis-disubstituted product being kinetically favoured. The higher selectivities observed for cyclisation to benzylic positions might be explained by faster interconversion of the iodides and/or an increased preference for the larger phenyl substituent (versus methyl) to be equatorial. However, since intermediates in the proposed reaction pathway were never observed, we are unable to probe these issues further.

Having successfully investigated the scope of the C-H amination in terms of substrate reactivity, attention was focused on the main goal of the research, namely to perform the side-chain amination of cyclic amines. The sulfamides of the commercially available $( \pm$ )-coniine 3a and 2-(2-phenylethyl)piperidine $3 \mathbf{b}$ were synthesised in two steps via their sulfamoyl chlorides. Exposure of the sulfamides to the optimised reaction conditions successfully gave rise to the $\mathrm{C}-\mathrm{H}$ aminated products $\mathbf{4 a}$ and $\mathbf{4 b}$ in good yields and moderate diastereoselectivity (Scheme 2). Again, complete regioselectivity was observed for the formation of the 1,6-HAT product, with no evidence of the formation of the 1,5-HAT product. X-ray crystal structures of 4a and $\mathbf{4 b}$ confirmed the major diastereomer to be the cis isomer $(\mathrm{ESI} \dagger)$.

Variation in both the side-chains and the saturated amine heterocycle was then examined more broadly. Non-commercial 2-alkyl amines were readily prepared from the simple unsubstituted cyclic amines in a single step using the method of Seide ${ }^{29}$ prior to conversion to the sulfamide using a one-pot procedure. ${ }^{28}$ Cyclisation of the longer 2-pentyl and 2-heptyl substrates proceeded smoothly to give the $\mathrm{C}-\mathrm{H}$ aminated products $\mathbf{4 c}$ and $\mathbf{4 d}$ respectively in good yields. Next, the choice of cyclic amine was investigated. The $\mathrm{C}-\mathrm{H}$ amination protocol was successful with smaller (pyrrolidine, 4e) and larger (azepane, $\mathbf{4 f}$ and $\mathbf{4 g}$ ) ring systems, heteroatom-containing rings (morpholine, $\mathbf{4 h}$ and $\mathbf{4 i}$ ) and saturated and aromatic bicyclic structures (octahydrocyclopena[c]pyrrole, $\mathbf{4 j}$, and 1,2,3,4-tetrahydroisoquinoline 4k). In all cases the major diastereomer formed in a ca. 2:1 to $3: 1$ ratio was the cis isomer, confirmed by X-ray analysis and/or NMR spectroscopy (ESI $\dagger$ ). The reaction failed, however, with derivatives of $N$-methyl piperazine, which led to a complex mixture of products attributed to the oxidatively labile nature of the tertiary alkyl amine.

The tetraponerines 5 are a series of eight closely related tricyclic alkaloids isolated from the venom secreted by pseudomyrmecine ants of the genus Tetraponera. These compounds have been shown to display both insecticidal and cytotoxic 

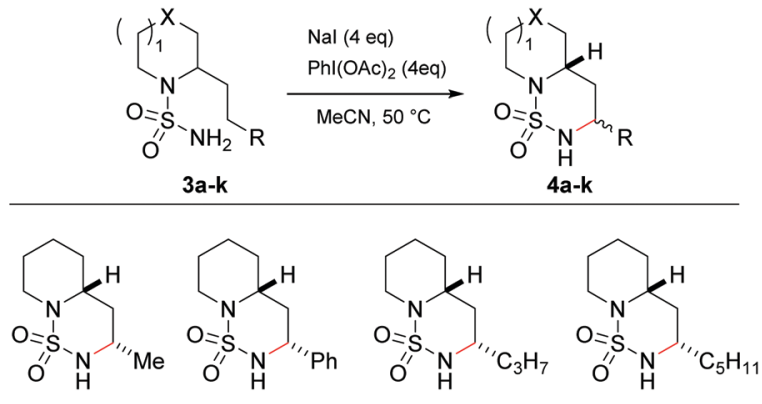

4a, $61 \%$

4b, $67 \%$

4c, $54 \%$

$67: 33 \mathrm{dr}$ 69:31 dr

$67: 33 \mathrm{dr}$

4d, $68 \%$

$67: 33 \mathrm{dr}$
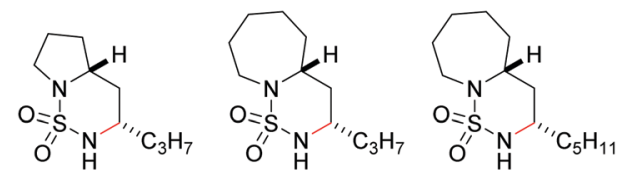

4e, $60 \%$

4f, $58 \%$

4g, $61 \%$

$67: 33 d r$

$69: 31 d r$

$67: 33 d r$
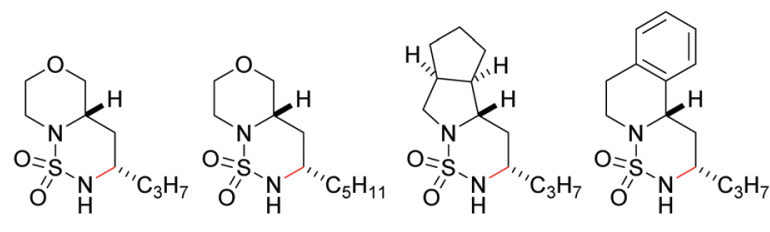

$\begin{array}{llll}\mathbf{4 h}, 48 \% & \mathbf{4 i}, 59 \% & \mathbf{4 j}, 68 \% & \mathbf{4 k}, 39 \% \\ 63: 37 \mathrm{dr} & 64: 36 \mathrm{dr} & 64: 36 \mathrm{dr} & 75: 25 \mathrm{dr}\end{array}$

Scheme 2 Substrate scope for the side-chain amination of 2-alkyl amines.

activities, making them highly desirable targets for synthesis. ${ }^{30,31}$ There have been several reported racemic ${ }^{31,32}$ and asymmetric ${ }^{33-41}$ syntheses of the tetraponerine alkaloids and it has been identified that 1,3-diamines of type 6 are viable precursors to the natural products (Scheme 3). ${ }^{31,34,35}$

Tetraponerine $\mathrm{T} 8 \mathrm{5a}$ represents the most abundant component isolated from the pseudomyrmecine venom. To demonstrate the utility of our $\mathrm{C}-\mathrm{H}$ amination protocol, we sought to access 1,3-diamine 6 which would in turn allow the synthesis of the natural product. Deprotection was achieved by heating cyclic sulfamide 4d (Scheme 2) in neat 1,3-propanediamine, which resulted in transamidation to reveal the free 1,3-diamine (Scheme 4). ${ }^{22,24}$ The crude mixture was then reacted with 4-bromobutanal which initiated $N$-alkylation followed by subsequent aminal formation to furnish 5a, the tricyclic alkaloid $( \pm)-\mathrm{T} 8$, in just four steps from piperidine (overall $2.5 \%$ yield): to our

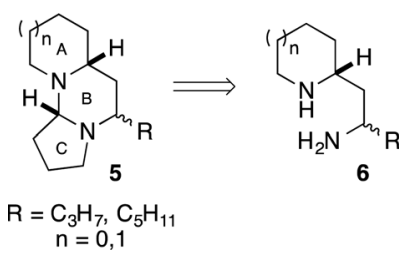

Scheme 3 Retrosynthetic disconnection for tetraponerine alkaloid synthesis.

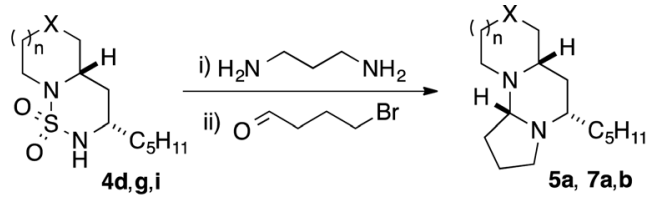

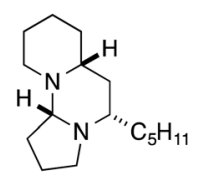

$5 a,( \pm)$ T8, 24\% $>95: 5 \mathrm{dr}$

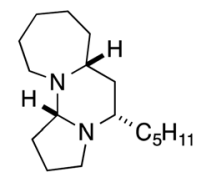

$7 a, 17 \%$ $>95: 5 \mathrm{dr}$

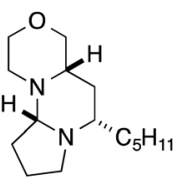

$7 \mathrm{~b}, 19 \%$ $>95: 5 \mathrm{dr}$
Scheme 4 Synthesis of $( \pm)$-T8 $5 \mathbf{a}$ and non-natural analogues.

knowledge this is the shortest synthesis of $( \pm)$-T8 from commercial materials to date.

Moreover, our approach lends itself readily to the construction of non-natural analogues, of which there have been few reports in the literature. ${ }^{32,42}$ Deprotection of cyclic sulfamides $\mathbf{4 g}$ and $4 \mathbf{i}$ followed by condensation with bromobutanal gave rise to the novel analogues containing azepane $7 \mathbf{a}$ and morpholine $\mathbf{7 b}$ rings respectively, again in just four steps from the parent amine azepane/morpholine. Variation in the C-ring and B-ring substituent should be accessible employing homologous bromoalkanals $^{43}$ and alternative alkyl-substituted sulfamides. This demonstrates the utility of our method for the rapid exploration of biologically-relevant chemical space.

In conclusion we have demonstrated a general and efficient method for the synthesis of 1,3-diamines by radical translocation guided by sulfamides. Most significantly, this allows for side chain functionalisation of simple 2-alkyl cyclic amines to complex 1,3-diamine derivatives. We have demonstrated the potential of this method in a concise four-step synthesis of the natural tetraponerine alkaloid T8 along with two non-natural analogues.

We thank EPSRC (EP/P016618/1 and EP/N025652/1) for funding, and Dr Chris Pask for the crystal structure determinations.

\section{Conflicts of interest}

There are no conflicts to declare.

\section{Notes and references}

1 (a) X. Ji and H. Huang, Org. Biomol. Chem., 2016, 14, 10557-10566For examples of recent synthetic approaches, see: (b) C.-Y. Wu and M.-H. Xu, Org. Lett., 2019, 21, 5035-5039; (c) K.-N. Li, A. E. Weber, L. Tseng and S. J. Malcolmson, Org. Lett., 2017, 19, 4239-4242; (d) Y. Liu, Y.-J. Xie, H.-L. Wang and H.-M. Huang, J. Am. Chem. Soc., 2016, 138, 4314-4317.

2 H. Morita, Y. Hirasawa, T. Shinzato and J. Kobayashi, Tetrahedron, 2004, 60, 7015-7023.

3 H. Kobayashi, K. Shin-ya, K. Furihata, Y. Hayakawa and H. Seto, Tetrahedron Lett., 2001, 42, 4021-4023.

4 D. N. Zalatan and J. D. Bois, Top. Curr. Chem., 2010, 292, 347-378.

5 J. L. Jeffrey and R. Sarpong, Chem. Sci., 2013, 4, 4092-4106.

6 (a) A. W. Hofmann, Ber. Dtsch. Chem. Ges., 1883, 16, 558-560; (b) K. Löffler, Ber. Dtsch. Chem. Ges., 1910, 43, 2035; (c) M. E. Wolff, Chem. Rev., 1963, 63, 55-64. 
7 C. G. Francisco, A. J. Herrera and E. Suárez, J. Org. Chem., 2003, 68, 1012-1017.

8 R. Fan, D. Pu, F. Wen and J. Wu, J. Org. Chem., 2007, 72, 8994-8997. 9 Q. Qin and S. Yu, Org. Lett., 2015, 17, 1894-1897.

10 N. R. Paz, D. Rodríguez-Sosa, H. Valdés, R. Marticorena, D. Melián, M. B. Copano, C. C. González and A. J. Herrera, Org. Lett., 2015, 17, 2370-2373.

11 C. Martínez and K. Muñiz, Angew. Chem., Int. Ed., 2015, 54, $8287-8291$.

12 E. A. Wappes, S. C. Fosu, T. C. Chopko and D. A. Nagib, Angew. Chem., Int. Ed., 2016, 55, 9974-9978.

13 For a review, see: G. Kumar, S. Pradhan and I. Chatterjee, Chem. Asian J., 2020, 15, 651-672.

14 D. N. Zalatan and J. D. Bois, Synlett, 2009, 143-146.

15 S. M. Paradine, J. R. Griffin, J. Zhao, A. L. Petronico, S. M. Miller and M. C. White, Nat. Chem., 2015, 7, 987-994.

16 M. A. Short, J. M. Blackburn and J. L. Roizen, Angew. Chem., Int. Ed., 2018, 57, 296-299.

17 S. Sathyamoorthi, S. Banerjee, J. Du Bois, N. Z. Burns and R. N. Zare, Chem. Sci., 2018, 9, 100-104.

18 E. Del Castillo, M. D. Martínez, A. E. Bosnidou, T. Duhamel, C. Q. O'Broin, H. Zhang, E. C. Escudero-Adán, M. MartínezBelmonte and K. Muñiz, Chem. - Eur. J., 2018, 24, 17225-17229.

19 S. K. Ayer and J. L. Roizen, J. Org. Chem., 2019, 84, 3508-3523.

20 W. Shu, H. Zhang and Y. Huang, Org. Lett., 2019, 21, 6107-6111.

21 Z.-Y. Ma, L.-N. Guo, Y. You, F. Yang, M. Hu and X.-H. Duan, Org. Lett., 2019, 21, 5500-5504.

22 K. Kiyokawa, S. Nakamura, K. Jou, K. Iwaida and S. Minakata, Chem. Commun., 2019, 55, 11782-11785.

23 T. Kurokawa, M. Kim and J. Du Bois, Angew. Chem., Int. Ed., 2009, 48, 2777-2779.

24 T. Duhamel, M. D. Martínez, I. K. Sideri and K. Muñiz, ACS Catal., 2019, 9, 7741-7745.

25 M. A. Short, M. F. Shehata, M. A. Sanders and J. L. Roizen, Chem. Sci., 2020, 11, 217-223.

26 D. Bafaluy, Z. Georgieva and K. Muñiz, Angew. Chem., Int. Ed., 2020, 59, 14241-14245.
27 For a 2-step synthesis: H. Lu, H. Jiang, L. Wojitas and X. P. Zhang, Angew. Chem., Int. Ed., 2010, 49, 10192-10196, followed by treatment with aq. $\mathrm{NH}_{4} \mathrm{OH}$. See ESI†.

28 For a one-pot synthesis: M. H. Bolli, C. Boss, C. Binkert, S. Buchmann, D. Bur, P. Hess, M. Iglarz, S. Meyer, J. Rein, M. Rey, A. Treiber, M. Clozel, W. Fischli and T. Weller, J. Med. Chem., 2012, 55, 7849-7861.

29 A. Paul and D. Seidel, J. Am. Chem. Soc., 2019, 141, 8778-8782.

30 (a) J. C. Braekman, D. Daloze, J. M. Pasteels, P. van Hecke, J. P. Declercq, V. Sinnwell and W. Francke, Z. Naturforsch., C: J. Biosci., 1987, 42, 627-630; (b) P. Merlin, J. C. Braekman, D. Daloze and J. M. Pasteels, J. Chem. Ecol., 1988, 14, 517-527.

31 I. Bosque, J. C. Gonzalez-Gomez, M. I. Loza and J. Brea, J. Org. Chem., 2014, 79, 3982-3991.

32 J. T. Kim, J. Butt and V. Gevorgyan, J. Org. Chem., 2004, 69, 5638-5645.

33 A. B. Charette, S. Mathieu and J. Martel, Org. Lett., 2005, 7, 5401-5404.

34 I. Bosque, J. C. Gonzalez-Gomez, A. Guijarro, F. Foubelo and M. Yus, J. Org. Chem., 2012, 77, 10340-10346.

35 S. G. Davies, A. M. Fletcher, I. T. T. Houlsby, P. M. Roberts and J. E. Thomson, J. Org. Chem., 2017, 82, 6689-6702.

36 R. Stragies and S. Blechert, J. Am. Chem. Soc., 2000, 122, 9584-9591. 37 J. C. O. Pacheco, A. Lipp, A. M. Nauth, F. Acke, J. P. Dietz and T. Opatz, Chem. - Eur. J., 2016, 22, 5409-5415.

38 I. Strassnig, K. Körber, U. Hünger and H. Kunz, Synthesis, 2015, 2299-2316.

39 H. Takahata, M. Kubota and N. Ikota, J. Org. Chem., 1999, 64, 8594-8601.

40 C. Yue, I. Gauthier, J. Royer and H.-P. Husson, J. Org. Chem., 1996, 61, 4949-4954.

41 P. Macours, J. C. Braekman and D. Daloze, Tetrahedron, 1995, 51(1415), 1428.

42 A. Rouchaud and J.-C. Braekman, Eur. J. Org. Chem., 2009, 2666-2674.

43 R. W. Alder, E. Heilbronner, E. Honegger, A. B. McEwen, R. E. Moss, E. Olefirowicz, P. A. Petillo, R. B. Sessions and G. R. Weisman, J. Am. Chem. Soc., 1993, 115, 6580-6591. 